\title{
Skin Colour: \\ Does it Matter in New Zealand? ${ }^{1}$
}

\author{
Paul Callister
}

\section{Introduction}

Pick up any official New Zealand publication which includes photographs representing the population and it is highly likely that the people featured will have visible characteristics, including skin colour, that are stereotypically associated with the main ethnic groups living in this country. Equally, examine official reports which consider differences in outcomes between groups of people, such as in health and education, and it is very likely that ethnicity will be a key variable in the analysis. But it is extremely unlikely that skin colour will be explicitly mentioned in either type of report.

This article explores three areas where skin colour might matter. First, with reference primarily to US literature, the question of the role of skin colour in discrimination and, ultimately, economic and health outcomes is examined. Then, turning to New Zealand, there is a discussion of whether skin colour is a factor in why those responding to official surveys who identify themselves as 'Māori only' have, on average, worse outcomes than those reporting Māori plus other ethnicities. Finally, two connected health issues are looked at. One is skin colour and the risk of skin cancer; and the second is the hypothesised, but still controversial, links between skin colour, sun exposure, vitamin D production and an inverse risk of developing colorectal cancer. Two main questions are asked in this article. First, in contrast with many other countries, why in recent years have researchers and policy makers in New Zealand been averse to discussing and researching skin colour? Second, is there a case to be made for the use of measures other than self-identified ethnicity - such as skin colour - in official statistics and other large surveys, including health-related surveys?

\section{Background}

Most governments collect some information on ethnicity or race. In a global comparison of census questionnaires, Morning (2008) shows that over half (56\%) asked about ethnicity, $15 \%$ asked about race, $7 \%$ were based on ancestry, while only $2 \%$ asked directly about skin colour. However, Morning notes that while ethnicity may be used in the wording of many questions, often the possible responses include colour-related categories. Examples include 'black' and 'white', often alongside responses that could be seen as 'race' or 'nationality' groupings, such as Indian or Chinese. For instance, the British census has categories such as 'White British' and 'White Irish', as well as 'Black British', while the Canadian census has 'black' and 'white' in its list of tickboxes. Equally, race-based collections, such as in the US, include 'black' and 'white' response options.

Before New Zealand shifted to culturally defined ethnicity, in common with other countries, race, based primarily on ancestry, was the foundation of New Zealand statistical collections. Mixing between races was recognised early on, with nineteenth-century census data identifying and separating out 'half-castes'. According to Kukutai and Didham (2007), although information on birthplace was routinely collected, national origin differences were minimised in racial determinations, at least for people considered white. Guidelines for the race question in the 1936 census advised that: 'All persons of "white" race should enter "European", irrespective of whether they are of New Zealand, English, Scottish, Irish, Frenchman, United States, or other stock.' The 'coloured' races, which included, among others, Māori, Chinese and 'Negros', were separately identified. Yet skin colour-related terms such as 'black' and 'white'

1 A more detailed version of this article can be found at http://callister. co.nz/skin-colour.pdf 
never explicitly became part of official language in the discussion of the composition of the New Zealand population. Also, unlike in countries such as Canada, the expression 'visible minority', a term referring to nonwhite groups, has not been used in New Zealand.

Despite skin colour not being an explicit part of $\mathrm{New}$ Zealand's historical official statistical output, unofficially - and sometimes officially - skin colour is often talked about. In recent years, primarily in relation to the growth of Māori and Pacific groups, there has been much discussion of the 'browning of New Zealand'. In the sporting arena there is sometimes mention of the 'browning' of teams such as the All Blacks and the Silver Ferns, but also at times there have been questions raised about players in the Māori All Blacks, suggesting the 'whitening' of the team members.

Discussing New Zealand's historic migration policy, Te Ara, the official electronic encyclopaedia of New Zealand, notes that 'much as New Zealand tried to keep its immigrants white through assisted migration schemes and entry permits, such a policy was hard to enforce and even harder to defend'. ${ }^{2}$ Gagnon (2007) suggests that in the major developed countries, Australia, Canada, the US and western European countries, 'whiteness' is a core part of official national identity. This is the viewpoint put forward by Hage (1998) in Australia. He talks about the concerns 'white Australians' feel in the face of declining power in a multicultural nation. ${ }^{3}$

But 'whiteness' is a concern not only in former European colonies. In many parts of Asia some groups try to develop or maintain light-coloured skin. It is believed that a lighter complexion is associated with wealth and higher education levels, whereas darker skin suggests being a low-income, outdoor worker. In contrast, in countries such as New Zealand and Australia, the use of solaria and tanning lotions suggests that there are people who value some aspects of darker skin and wish to change their natural skin colour. In these higher income countries such tans may be associated with leisure rather than with manual outdoor work.

The term 'white' can be symbolic rather than strictly representative of skin colour. For example, in a study

2 http://www.teara.govt.nz/NewZealanders/NewZealandPeoples/ HistoryOfImmigration/15/en

3 Hage defines white people as those of European origin; the rest of the population are 'Third World-looking people' of Samoan intermarriage in New Zealand, Keddell (2006) comments that New Zealand-born Samoans whose parents are both Samoan are often excluded and marginalised by older, Island-born Samoans. She suggests that these children are perceived as being 'fia palagi'; that is, wanting to be palagi or, as Keddell notes, 'white'.

While skin colour has not been part of official statistics collection, there are some examples of the use of skin colour by specific agencies in New Zealand. For example, skin colour is included in New Zealand's human rights laws. There are 13 prohibited grounds of discrimination set out in section 21 of the New Zealand Human Rights Act 1993. These include sex and disability, but also ethnic or national origins, race and colour. However, the most common example of reference to skin colour is likely to be its use by the police. When the police are endeavouring to track down a suspect they will often resort to physical descriptions. It is not uncommon to hear the police describe a suspect as 'Caucasian', meaning a white-skinned person.

The police are not the only ones constructing an individual's ethnicity. Various 'others' who do so, such as employers, landlords, teachers and doctors, are important gatekeepers in society. Often this construction of ethnicity by others will be based on visible, or recognisable, characteristics, including skin colour. Some of the 'others' will be young people. A survey carried out by Thomas and Nikora (1991) investigated the characteristics associated with the terms 'Māori' and 'Pākehā' among New Zealand high school students. The data showed that skin colour was one of the methods of determining who belonged to a particular ethnic group. Among both Pākehā and Māori students the main characteristics associated with being Pākehā were skin colour (Pākehā 57\%, Māori $51 \%$ ), and culture, customs and lifestyle (Pākehā 33\%, Māori 15\%). Among Māori respondents, the most common attributes associated with being Māori were culture, customs, lifestyle (71\%) and Māori language (61\%). However, other attributes included skin colour and appearance (48\%), accent (29\%), descent (25\%) and tribal and kin affiliations (20\%). Among Pākehā respondents, colour and appearance $(49 \%)$ was most frequently used to describe Māori people, followed by culture, customs and lifestyle (35\%), accent (28\%) and language (17\%). 
Yet there are many examples suggesting physical characteristics may not be a good predictor of ethnicity in New Zealand. For instance, in 2002 Moana Jackson commented that there was much surprise, particularly amongst Māori, that Keith Abbott, the policeman who shot Steven Wallace in Waitara, was Māori (with descent from Ngāti Kahungunu). This surprise was presumably due to his physical characteristics. This realisation complicated discussions about possible racism as a factor in the shooting. Mana magazine, when announcing a top female Māori scholar in 2002 (Mana, 2002, p.22), focused initially on physical characteristics but then noted: 'Don't be fooled by the blond hair and the green eyes. She's Māori, really, and is our top scholar for the year.'

\section{Skin colour - discrimination and outcomes}

As already noted, employers, teachers, the police, landlords and health care providers are important societal gatekeepers. These people can be discriminatory in their behaviour. Such discrimination can occur on the basis of a wide range of characteristics, including age, sex, religious belief, surname, style of clothing and skin colour. Some of these can be seen as 'visible' characteristics, but they are probably more realistically called 'recognisable' characteristics. However, questions then arise as to why some characteristics are recognised; who is doing the recognising; and why some people might exhibit discriminatory behaviour. It tends to be assumed that people from the dominant culture will be doing the recognising; that they will be basing this recognition on stereotypes; and that some will then exhibit discriminatory behaviour based on these stereotypes. But everyone in society, including those who are part of ethnic minorities, will be doing some form of recognising and possibly forming discriminatory views or undertaking discriminatory actions based on such recognition.

In New Zealand, as noted, colour is one of the prohibited grounds of discrimination. The Human Rights Commission notes that a complaint relating to colour will usually also relate to the grounds of race. A search of the database compiled by the commission shows that few complaints have been made on the basis of skin colour alone, and that colour is one of the grounds on which they receive the least number of complaints. In the reporting year ending 30 June 2003 , colour was the grounds in just $2 \%$ of unlawful discrimination cases; in 2004, 1\%; and in both 2005 and 2006, $0.8 \%$. During the year 1 July 2006 to 30 June 2007 the commission received 14 complaints related to colour. But while some complaints are based on references to dark skin, some specific cases suggest that colour issues are complex. For example, in the 2007 year there was a complaint about an advertisement in which a woman said to a 'freckled red hair' man, 'get your dirty freckled hands off me'. Another example concerned harassment in a text message referring to a person's 'yellow skin'.

It is easier to find literature from the United States which considers skin colour as an important variable when examining economic and social outcomes, including how discrimination may influence these outcomes. In a review article covering employment discrimination, segregation and health, Darity (2003) points to a number of mainly cross-sectional studies which show that blacks with dark skin, as well as (in some situations) darker-skinned Hispanics, fare worse on a number of social and economic indicators than their lighter-skinned counterparts. But there are also US studies which do not find strong effects of skin colour in relation to discrimination (e.g. Krieger et al., 1998). Some researchers, however, propose that this is due to African Americans being treated as black regardless of their tone or shade. This potentially relates back to the 'one drop' thinking in the United States, where one 'drop' of 'black blood' makes a person black.

New Zealand research on racism has not directly considered skin colour. As an example, a study of self-perceived racial discrimination on self-determined health outcomes used data from the 2002/03 New Zealand Health Survey and was based on ethnicity (Harris et al., 2006). In this study, Māori reported the highest prevalence of 'ever' experiencing any form of racial discrimination (34\%), followed by Asians (28\%), then Pacific people (25\%) and finally Europeans/Others (15\%). However, perhaps hinting that some physical characteristics might matter, the authors note that the 'European/Other' category contained a number of nonEuropeans. Yet this study also gives some indication 
that skin colour may not be the critical variable. If skin colour was, then potentially the 'brown' Pacific and Māori populations might be subject to similar levels of discrimination. It seems a wider range of characteristics are influencing discriminatory behaviour or perceptions of discrimination.

\section{Single and multiple ethnicity and out- comes}

Moving back to the American context, two hypotheses have been put forward to explain the effect of mixed race on a variety of outcomes, including health status. One is that mixed-race individuals will be at greater risk of poor outcomes than those who affiliate with a single race because of stresses associated with a mixed identity. The other theory is that outcomes will lie between those of the two single groups. Many factors are likely to be influencing these outcomes, but variations in skin colour could be important, either directly or indirectly.

In New Zealand there has been relatively limited use made to date of single versus dual and multi-ethnic responses when analysing advantage and disadvantage. However, early work by Gould $(1996,2000)$ suggested a gradient of disadvantage in relation to degree of 'Māoriness'. In his 1996 paper Gould associated Ngāi Tahu's integration into European society with their relative success when compared with other iwi. However, while other people have talked about Ngāi Tahu as being the 'white tribe', skin colour was not discussed by Gould in any of his papers.

In a number of papers, Chapple (e.g. 2000) divided the Māori ethnic group into two groups, 'sole Māori' and 'mixed Māori', and found better outcomes for 'mixed Māori'. Chapple raised the idea that the disadvantage amongst Māori is concentrated in a particular subset: those who identify only as Māori, who have no educational qualifications, and who live outside major urban centres. Again, skin colour was not a feature of these studies.

However, Kukutai (2003) suggests that social policy makers should not put much weight on categories such as 'Māori only' and 'Māori plus other ethnic group(s)'. Using survey data and a system of selfprioritisation, Kukutai showed that those individuals who identified as both Māori and non-Māori, but more strongly with the latter, tended to be socially and economically much better off than all other Māori. In contrast, those who identified more strongly as Māori had socio-economic and demographic attributes that were similar to those who recorded only Māori as their ethnic group. Kukutai's work shows that some people recording multiple ethnic responses feel a strong sense of belonging in more than one ethnic group. For others, however, a stronger affiliation is felt with one particular ethnic group. While not discussed directly in the study, factors such as visible difference, including skin colour, may influence such decisions.

What is causing different outcomes between those recording only Māori ethnicity and those recording Māori and European responses? We do not know. No one single factor is likely to be a driver, but skin colour, in a variety of ways, may exert some influence. For example, it may be that those who 'look more Māori' (or look more 'Pacific') are more likely to record only Māori (or Pacific) ethnicity in official surveys. If this is correct, and if discrimination is common in New Zealand, the Māori-only (or Pacific peoples) group would be more likely to suffer discrimination from police, landlords and healthcare providers.

\section{Skin colour, skin cancer, vitamin D and colorectal cancer}

The relationship between race or ethnicity and health outcomes has always been contentious. Medical research suggests there are few diseases that have a simple genetic determination, one example being that of Huntingtons, a rare, inherited neurological disorder. Whilst simple genetic mutations may be found to vary between ethnicl racial groups, most genetic factors show greater variation within than between ethnic groups (Pearce et al., 2004). However, one area in which genetics has a clear impact is skin colour.

Skin colour has been associated with the risk of developing skin cancer, including melanoma. In both New Zealand and Australia there has been debate in both the medical world and the media about whether there is a strong causal, but inverse, relationship between sun exposure, vitamin $\mathrm{D}$ production and cancer. The theory is that sun exposure may protect against some forms of cancer, in particular colorectal cancer. In a report commissioned by the Cancer Society, Scragg (2007, p.21) suggests: 
The strong evidence from studies showing an inverse association between vitamin $\mathrm{D}$ and colorectal cancer, when combined with similar (albeit limited) findings from studies of total cancer incidence and mortality, suggest that cancer incidence and mortality in New Zealand can be expected to decline if levels of vitamin $\mathrm{D}$ in the population are increased.

As to why skin colour may be lighter amongst some groups: there is some scientific evidence to suggest that humans emerged from Africa to colonise other areas some 70,000 years ago, and scientists suggest that the migrating Africans were likely to have had dark, highly reflective skin and black hair. It is hypothesised that as this group moved from equatorial regions northwards into central Asia, then into Europe, eastern Asia and the polar north, dark skin became a liability. At higher latitudes the lower angle of the sun, the longer and darker winters and the need to wear warm clothing may have made those who had darker skin deficient in vitamin $\mathrm{D}$, which is mainly produced by the action of ultraviolet radiation (UV) on cholesterol in the skin. Vitamin D is essential for normal calcium metabolism and chronic deficiency causes rickets in children.

But light-coloured skin raises the risk of skin cancer, including melanoma, especially when light-skinned people migrate to areas with strong UV radiation. While skin cancer is a risk in Europe, people from Europe have migrated to countries such as Australia and New Zealand where UVR levels are much higher in the summer than at comparable latitudes in the northern hemisphere (McKenzie et al., 1996). In New Zealand, the descendants of these migrants include New Zealand Europeans but, through intermarriage, also Māori, Pacific people and Asians.

Historical data suggests that malignant melanoma was rare amongst Māori. However, while numbers are still small, cancer registration data now suggests that melanoma may be increasing, from a small base, for Māori. If skin colour is a factor behind the rise in Māori melanoma rates, there are two possible explanations. The first is that through historic and ongoing intermarriage there is a growing group of Māori with light-coloured skin who are at risk of developing melanoma. It is also possible that there is now a group of light-skinned people who had Mãori ancestry, but in the past did not claim Māori ethnicity.
But exposure of the skin to the sun is important for producing vitamin $\mathrm{D}$, of which sunlight is the main source. Analysing blood samples collected as part of the 2002 National Children's Nutrition Survey, Rockell et al. (2005) found that Māori and Pacific children have, on average, lower vitamin D levels than European children. This lower level of vitamin D amongst Māori and Pacific children was assumed to be the result of the amount of melanin, or skin darkness, and lack of exposure to the sun. However, a range of other factors may be influencing levels, including prevalence of obesity, type of diet and level of exercise. The relationship of sun exposure and skin type in New Zealand to these lower levels of vitamin $\mathrm{D}$ has not yet been validated against an objective measure of skin colour.

Colorectal cancer is a major cancer type and the leading cause of non-tobacco-attributable cancer mortality for both men and women (Blakely et al., 2007). Just as there are differences in melanoma rates for Māori and non-Māori, there are also differences in the rates, and in trends, of colorectal cancer. Blakely et al. show that when considering age-standardised mortality rates (within the 1-74 age group), Māori men had a lower rate than European men for the 1981-84 cohort. However, mortality rates have been increasing for Māori men and decreasing for European/Other men, so that for the 2001-04 cohort colorectal cancer mortality rates were higher for Māori men. For Māori women, the estimates move around more, but for the 2001-04 cohort Māori rates were still marginally below that of European/Other women. The increasing rates for Māori undermine the vitamin $\mathrm{D}$ hypothesis, unless sun exposure has changed over time, through, perhaps, rural-urban migration and/or fewer Māori working in outdoor occupations, or because Māori with dark skin have inappropriately been affected by 'sunsmart' promotions which suggest limiting sun exposure at peak UV intensity. However, there are likely to be many confounders, including change of diet, physical activity and obesity levels. Nevertheless, vitamin D produced by sun exposure may still be of some importance in relation to colorectal cancer rates, and skin colour may be a factor in obtaining adequate levels of vitamin D from the sun.

One possible outcome of the debate about vitamin D and its potential protective effect is that sun exposure, including sun protection, messages should differ according to ethnic group. One suggestion might be 
specifying that Māori and Pacific people are not at risk, or are at lesser risk, from melanoma, so do not need to 'cover up' in the summer in the same way as Europeans. In fact, the argument could be that Māori and Pacific people should actively seek out sun exposure to protect themselves again colorectal cancer. But how good a predictor is ethnicity of particular skin types? In much of the New Zealand health discussions there seems to be an assumption that ethnicity is an excellent predictor of skin type. However, as yet we know little about the relationship. ${ }^{5}$ In the long term, if skin colour was collected on the official cancer registry, then the interaction of skin colour with cancer incidence and mortality could be assessed. But even if it turns out that there is a reasonable relationship at a group level, such data tells one little about risk factors for individuals within the group. It would be irresponsible, for example, to say that, given historic data showing Māori have a low (but growing) risk of melanoma, Māori (or Pacific people) as a group therefore do not need to cover up at peak UVR times in summer. That decision needs to be made in relation to individual characteristics, particularly skin colour. That is, there may be some Māori and Pacific people who should spend more time in the sun than they currently do to protect against some forms of cancer, but there will be other Māori and Pacific people who should carefully heed the summer sunsmart messages in order to protect against developing skin cancer.

\section{Conclusion}

Does skin colour matter? Ideally, in most, but not all, situations society should be colour-blind. Yet, despite skin colour not being part of any official measure of ethnicity in New Zealand, it seems likely that many people are using skin colour, along with other recognisable characteristics, on a day-to-day basis in defining either their own ethnic identity or other people's identity. Expressions such as the 'browning' of New Zealand also suggest that skin colour is an important concept in some contexts. In New Zealand there seems to be a common assumption that Māori and Pacific people are brown and that, equally, Europeans are white. It is also assumed by some that those who

5 In 2007 the Health Research Council funded a project titled 'Quantifying the association between sun exposure and vitamin D status in New Zealanders', which will consider skin type. record 'New Zealander' ethnic responses in surveys are white, and that migrants from Europe are also white. Yet the small amount of available evidence suggests that there may be much variation in skin colour within broad ethnic groups.

On the basis of mainly US research, it seems likely that skin colour, along with other recognisable characteristics, is a factor in discriminatory behaviour. However, research would be needed to test whether this is important in New Zealand. If skin colour is important, then it is likely, as an example, that not all Māori would face the same degree of discrimination. It is possible that those who fit a particular visual stereotype would face the greatest difficulties. This may be one factor in why those recording both Māori and European ethnicities have, on average, better outcomes than those who record 'Māori only'. To help reduce ethnic inequalities it is important that we understand all the contributing factors to the disadvantages faced by particular groups.

This article raises some questions as to why skin colour is thought about in some contexts, but appears unable to be discussed in others. The main area where it seems that it is not able to be discussed is within the research and policy community. To some degree this seems due to New Zealand moving from thinking about race in official contexts and switching to a discourse focusing on culturally-constructed ethnicity. Skin colour has become a hidden variable when considering differing outcomes for groups within New Zealand. But if we did talk more openly about skin colour, should we go one step further and start collecting such information in official surveys, especially in health data sets such as the Cancer Registry? Skin colour is likely to be useful for some medical research, such as the possible links between vitamin D levels and cancer. It is also likely to be very useful when considering discrimination. But there would be problems in collecting such data. One is simply technical: how would we get objective data? But there may be other reasons for not collecting such information. It may be that focusing more on skin colour would reinforce differences between people rather than help break them down. Just as collections of ethnic data may not only reflect ethnic groups but also create them through developing stereotypes based on behaviour, so too might collections that contain skin colour. 
As a first step, it would be worthwhile carrying out some qualitative work as to how individuals, especially young people, conceptualise ethnicity, including how they bring in considerations of skin colour alongside other influences. This would help us start to answer the question of whether skin colour matters in New Zealand.

\section{Acknowledgements}

I would like to thank David Bromell, Tony Blakely, Robert Didham, Gary Hawke, Judith Galtry and Tahu Kukutai for their insightful comments on an earlier longer version. However, all opinions expressed in this article are my own.

\section{References}

Blakely, T., M. Tobias, J. Atkinson, L-C. Yeh \& K. Huang (2007) Tracking Disparity: trends in ethnic and socioeconomic inequalities in mortality, 1981-2004, Wellington: Ministry of Health

Chapple, S. (2000) 'Māori socio-economic disparity', Political Science, 52 (2), pp.101-15

Darity, W.A. (2003) 'Employment discrimination, segregation, and health', American Journal of Public Health, 93 (2), pp.226-31

Gagnon, C. (2007) 'Whiteness and multiculturalism',http://www.ithaca.edu/gagnon/ whiteness/

Gould, J.D. (1996) 'Socio-economic differences between Māori iwi', Journal of the Polynesian Society, 105 (2), pp.165-83

_ (2000) 'Counting Māori', New Zealand Population Review, 26 (2), pp.1-19

Hage, G. (1998) White Nation: fantasies of white supremacy in a multicultural society, Sydney: Pluto

Harris, R., Tobias, M, Jeffreys, M. Waldegrave, K., Karlsen, S., \& Nazroo, J, (2006) 'Racism and health: The relationship between experience of racial discrimination and health in New Zealand', Social Science and Medicine, 63(6), pp. 1428-41

Jackson, M. (2003) ‘The part-Māori syndrome’, Mana, 52 (June-July), p.62

Keddell, E. (2006) 'Pavlova and pineapple pie: selected identity influences on Samoan-Pākehā people in
Aotearoa/New Zealand', Kōtuitui: New Zealand Journal of Social Sciences online, 1, pp.45-63

Krieger, N., S. Sidney \& E. Coakley (1998) 'Racial discrimination and skin color in the CARDIA study: Implications for public health research', American Journal of Public Health, 88, pp. 1308-13

Kukutai, T. (2003) The Dynamics of Ethnicity Reporting: Māori in New Zealand, Wellington: Te Puni Kōkiri

Kukutai, T. \& R. Didham (2007) 'Can national identity become ethnic identity? The case of the emerging New Zealander ethnic group', paper presented at the international conference on social statistics and ethnic diversity: 'Should we count, how should we count and why?', Montréal, 6-8 December

Mana (2002) 'Top scholar', Mana Magazine, 45 (April-May), p.22

McKenzie, R.L., G.E. Bodeker, D.J. Keep, M. Kotkamp \& J.H. Evans (1996) 'UV radiation in New Zealand: measured north to south differences, and relationship to other latitudes', Weather and Climate, 16 (1), pp.17-26

Morning, A. (2008) 'Ethnic classification in global perspective: a cross-national survey of the 2000 census round', Population Research and Policy Review online, http://www.springer.com/social+sciences/demography/ journal/11113

Pearce, N., S. Foliaki, A. Sporle \& C. Cunningham (2004) 'Genetics, race, ethnicity, and health', British Medical Journal, 328, pp.1070-2

Rockell, J.E. (et al.) (2005) 'Season and ethnicity are determinants of serum 25-hydroxyvitamin D concentrations in New Zealand children aged 5-14 y', Journal of Nutrition, 135, pp.2602-8

Scragg, R. (2007) 'Vitamin D, sun exposure and cancer: a review prepared for the Cancer Society of New Zealand', Wellington: Cancer Society, http://www.cancernz.org. nz/Uploads/VitaminD_UV_CancerReview_24Sept07. pdf

Thomas D.R. and L.W. Nikora (1991) 'Māori, Pākehā and New Zealander: conceptions of ethnic and national identity among New Zealand students', unpublished manuscript, Hamilton: Department of Psychology, University of Waikato 
Paul Callister is a senior research fellow in the Institute of Policy Studies at Victoria University of Wellington. His main research interests lie in the broad area of social policy and include issues relating to education, work-life balance, parental leave, migration patterns, family change and labour market behaviour. He can be contacted at paul.callister@vuw.ac.nz.

\section{FREE AND FRANK: Making the New Zealand Official Information Act 1982 work better by Nicola White}

The New Zealand Official Information Act 1982 is frequently hailed as one of this country's most significant constitutional reforms. It is praised as world-leading in its refusal to contemplate that any category of government information might be completely immune from the prospect of public disclosure.

But for those who work with the Act, either as seekers of information or as officials responding to requests, it is not an unqualified good - the working reality of the Act can be frustrating and timeconsuming, just as often as it is enlightening.

This book follows a two-year research project into the day-to-day operation of the Act. It examines the history of the Act's passage and subsequent development and reports the candid views of (anonymised) officials, politicians, academics, political advisers and 'regular seekers' of Official Information.

The result is a 'free and frank' picture of the operation of administrative and political processes around Official Information. It carries a sobering message about how those process, if not well-managed, can erode trust in government across time.

But the picture is not all bleak. The book concludes with proposals for change designed to build on the very real strengths of the system, to help it cope with the challenges of modern politics and the information age.

Nicola White has had nearly 20 years of close involvement with the theory and practice of the Official Information Act as a public sector lawyer and policy adviser. This research was carried out whilst she was a Senior Research Fellow at the Institute of Policy Studies in Victoria University's School of Government (2004-6).

Published - November 2007

Format - B5 Paperback, pp 318

ISBN - 1-877347-21-3

Price - $\$ 35.00$ (including P\&P within New Zealand)

To have a copy of Free and Frank: Making the New Zealand Official Information Act 1982 work better and an invoice sent to you, please email, phone, fax or mail your order to:

Institute of Policy Studies

Victoria University of Wellington

Email ipos@vuw.ac.nz

Telephone +64 44635307

Fax +64 44637413

P0 Box 600, Wellington

New Zealand 